[Agr. Biol. Chem. Vol. 31, No. 3, p. $261 \sim 266,1967]$

\title{
Glycosides and Oligosaccharides in the L-Rhamnose Series
}

\section{Part II. Syntheses of Certain $\alpha$-L-Rhamnosyl Disaccharides}

\author{
By Shintaro Kamiya, Sachiko Esaki and Misao Hama \\ Laboratory of Food Chemistry, Shizuoka Women's Junior College, Shizuoka \\ Received July 9, 1966
}

\begin{abstract}
An attempt was made to synthesize certain $\alpha$-L-rhamnosyl disaccharides. In this publication the following sugars were prepared by employing Helferich or Bredereck reaction; 6-O- $\alpha$-L-rhamnosyl-D-glucose (rutinose), 6-O- $\alpha$-L-rhamnosyl-D-galactose (robinobiose), 2-O- $\alpha$-L-rhamnosyl-D-glucose (neohesperidose), all of which are known as sugar portions of plant glycosides, 6-O- $\alpha$-L-rhamnosyl-D-mannose and 1-O- $\alpha$-L-rhamnosyl-D-fructose, both of which have not yet been found in nature.
\end{abstract}

\section{INTRODUCTION}

In order to study the substrate-specificity of $\alpha$-L-rhamnosidase induced in Aspergillus species, certain $\alpha$-L-rhamnosyl disaccharides were intended to synthesize. In this publication new synthetic methods of the following sugars, namely, 6-O- $\alpha$-L-rhamnopyranosyl-D-glucopyranose (rutinose), 6-O- $\alpha-\mathrm{L}$-rhamnopyranosyl-Dgalactopyranose (robinobiose), 2-O- $\alpha$-L-rhamnopyranosyl-D-glucopyranose, which are naturally occurring disaccharides, 6-O- $\alpha$-L-rhamnopyranosyl-D-mannopyranose and 1-O- $\alpha$-L-rhamnopyranosyl-D-fructopyranose, which have not been discovered in nature, are reported. Rutinose occurs as the sugar portion of a number of plant glycosides, e.g., rutin, linarin, diosmin, hesperidin, etc. This disaccharide may be readily liberated by hydrolysis of rutin with dilute acid ${ }^{11}$ or with enzyme which is formed in Rhamnus utilis ${ }^{21}$ and other plant species. Rutinose was chemically synthesized by $\mathrm{G}$. Zemplén. ${ }^{31}$

On the basis of this synthesis L-rhamnose in rutinose was originally assigned as the $\beta$ -

1) G. Zemplén and A. Gerecs, Ber., 71, 2520 (1938).

2) C. Charaux, Comp. Rend., 178, 1312 (1924).

3) G. Zemplén and A. Gerécs, Ber., 67, 2049 (1934). configuration, but it is now known to be the $\alpha$-form. ${ }^{4}$ Robinobiose is the sugar portion of the glycoside robinin which occurs in Robinia pseudoacacia flowers, ${ }^{51}$ Puerarea thunbergiana ${ }^{6}$ and several phaseolus species. The sugar was also synthesized chemically by G. Zemplén ${ }^{7 \prime}$ and was considered to contain $\beta$-link, but it is now assigned as $\alpha$-link. ${ }^{41} \quad$ Neohesperidose forms the glycosidic portion of neohesperidin, naringin and poncirin which are present in the peel of citrus.

In order to know the suitable synthetic method for $\alpha$-L-rhamnosyl disaccharides, an attempt was made to synthesize them by the following procedures, namely, Königs-Knorr reaction ${ }^{81}$ by the use of silver salt as a condensing agent in chloroform solution, Zemplén reaction ${ }^{71}$ by the use of mercuric acetate in benzene solution, Helferich reaction ${ }^{91}$ by the

4) P.A.J. Gorin and A.S. Perlin, Can. J. Chem., 37, 1930 (1959).

5) G. Zemplén and A. Gerécs, Ber., 68, 2054 (1934).

6) S. Hattori, M. Shimokoriya and M. Nakajima, Chem. Abstracts, 47, 705 (1953).

7) G. Zemplén, A. Gerécs and H. Flesch, Ber., 71, 2511 (1938).

8) W. Königs and E. Knorr, Sitzungsber. Bayr. Akad. Wiss., 30, 103 (1900); Ber., 34, 957 (1901).

9) B. Helferich and J. Zirner, Chem. Ber., 95, 2604 (1962). 
use of a mixture of mercuric cyanide and mercuric bromide in acetonitrile solution and Bredereck reaction ${ }^{101}$ by the use of silver perchlorate in nitromethane solution.

Essentially these reactions involve the elimination of a hydrogen halide (usually hydrogen bromide) between a substituted glycosyl halide and unsubstituted hydroxyl groups of a second monosaccharide in the presence of appropriate catalyst. The experiment was carried out on a microscale and the products were examined by paper chromatography.

In the case of Königs-Knorr reaction the main products were two orthoesters and only a small amount of rutinose was detected, and it was considered that this method was not suitable for $\alpha$-L-rhamnosyl disaccharide synthesis. In contrast, in the case of the other reaction the main product was rutinose, giving fortunately no orthoesters.

Especially the latter two procedures gave the best results and these methods were chiefly used in the following experiments. Rutinose ${ }^{3 !}$ was already synthesized chemically in 1934 by G. Zemplén by condensing 2,3,4-tri-O-acetyl- $\alpha$ L-rhamnosyl bromide with 2,3,4,6-tetra-Oacetyl- $\alpha$-D-glucosyl chloride, followed by treatment with mercuric acetate. But the present paper describes other new synthetic methods of rutinose. 2,3,4-Tri-O-acetyl- $\alpha$-L-rhamnosyl bromide $^{12}$ was condensed with $\beta-1,2,3,4$-tetra$\mathrm{O}$-acetyl-D-glucose ${ }^{11 !}$ by the Helferich reaction to form the mixture of sugar acetates, which upon deacetylation yielded a mixture of free sugars. On account of isolation and purification of rutinose carbon-column chromatography was applied to the sugar mixtures.

After adsorption of them on the column rutinose fractions were collected by stepwise elution with water and ethanol of various concentrations. Rutinose was obtained as an amorphous hygroscopic powder, which upon acetylation afforded a heptaacetate. On the

10) H. Bredereck, A. Wagner, G. Faber, H. Ott and J. Rauther, Chem. Ber., 92, 1135 (1959). other hand the configuration of synthetic rutinose has been confirmed as $\alpha$-type because specific rotation value of its oxidation product with periodic acid was in accordance with that of the oxidation product of natural rutinose.

Rutinose could also be synthesized by the similar manner in which only 1,2,3,4-tetra-Oacetyl- $\beta$-D-glucose ${ }^{111}$ was replaced by $1,2,3,5$ di-O-isopropylidene- $\alpha$-D-glucofuranose. ${ }^{13}$

Furthermore another synthetic route is described.

Condensation of 2,3,4-tri-O-acetyl- $\alpha$-Lrhamnosyl bromide ${ }^{12)}$ with 6-O-trityl-1,2,3,4tetra-O-actyl-D-glucose ${ }^{111}$ by the Bredereck reaction yielded the condensed products, which upon deacetylation and subsequent fractionation by carbon-column chromatography gave pure rutinose.

It was also led to crystalline heptaacetate. Robinobiose was chemically synthesized by G. Zemplén in 1934.

In this paper it was synthesized by the two different methods. 2,3,4-Tri-O-benzoyl- $\alpha$-Lrhamnosyl bromide ${ }^{14)}$ was condensed with 1,2:3,4-di-O-isopropylidene-D-galactose by the Helferich reaction to give a new crystalline 6- $\alpha$-(2, 3, 4-tri-O-benzoyl-L-rhamnosyl)-1, $2: 3,4$ di-O-isopropylidene-D-galactose. The latter compound lost its acetone and benzoyl groups upon mild acid and alkaline hydrolyses, respectively, and gave pure robinobiose. The configuration of the sugar was established as $\alpha$-type by its oxidation with periodic acid, which led through customary reactions to the same compound that was obtained similarly from rutinose.

Upon acetylation of robinobiose it is converted to the amorphous heptaacetate, which on treatment with titanium tetrachloride yielded $\alpha$-acetochlororobinobiose in crystalline form. An other synthetic route to robinobiose was also established. The condensation of 2,3,4-tri-O-acetyl- $\alpha$-L-rhamnosyl bromide with 1,2,3,4-di-O-isopropylidene- $\mathrm{D}$-galactose by the Helferich reaction led to the condensation 
products which, followed by deacetylation and deacetonation, afforded a mixture of free sugars. After treatment of them with carboncolumn chromatography robinobiose was obtained.

It was characterized as crystalline $\alpha$-acetochloroderivative. Similarly, 6-O- $\alpha$-L-rhamnosylD-mannose was prepared by Bredereck reaction condensing 2,3,4-tri-O-acetyl- $\alpha$-L-rhamnosyl bromide with 6 -trityl- $\beta$-1,2,3,4-tetra-O-acetylD-mannose. ${ }^{17)}$ Condensing products, after losing its protecting groups followed by fractionation by carbon column, gave amorphous hygroscopic 6-O- $\alpha$-L-rhamnosyl-D-mannose.

The configuration of the sugar was determined as $\alpha$-type by the similar procedure as described in the case of rutinose. In the case of 1-O- $\alpha$-L-rhamnosyl-D-fructose synthesis, 2,3 , 4 -tri-O-benzoyl- $\alpha$-rhamnosyl bromide was condensed with 2,3:4,5-di-O-isopropylidene-Dfructopyranose by Helferich reaction. As condensation product, $1-\alpha-(2,3,4$-tri-O-benzoylL-rhamnosyl)-2,3:4, 5-di-O-isopropylidene-Dfructopyranose was obtained in crystalline form. By losing protecting groups followed by purification by carbon column, 1-O- $\alpha-\mathrm{L}-$ rhamnosyl-D-fructose was given. It was characterized as a crystalline phenylhydrazone.

Neohesperidose was synthesized by Helferich reaction. Condensation of 2,3,4-tri-O-acetyl$\alpha$-L-rhamnosyl bromide with $\alpha$-1,3,4,6-tetra-Oacetyl glucose yielded condensed products, which by deacetylation and subsequent fractionation afforded a sirup which showed a single spot on paper chromatogram. It was reacetylated giving $\beta$-heptaacetyl derivative in crystalline form.

\section{EXPERIMENTAL}

1. Comparison of the synthetic methods of the $\alpha$-L-rhamnosyl disaccharide

Paper chromatography was carried out with paper using butanol : acetic acid : water $(4: 1: 2)$ as solvent and aniline hydrogen phthalate as spraying reagent.

i) Synthesis of rutinose by the Königs-Knorr reaction. Active silver oxide was prepared according to the procedure of $\mathrm{B}$. Helferich. To a mixture containing $1.05 \mathrm{~g}$ of $\beta$-1,2,3,4-tetraacetyl D-glucose, $0.75 \mathrm{~g}$ of silver oxide, $0.1 \mathrm{~g}$ of iodine and $0.3 \mathrm{~g}$ of Drierite in dry chloroform was added, with stirring, a solution of $1.2 \mathrm{~g}$ of 2,3,4-tri-O-acetyl- $\alpha$-L-rhamnosyl bromide in $5 \mathrm{ml}$ of chloroform. The mixture was shaken for 18 hours.

The sirup was treated with $5 \mathrm{ml}$ of $0.05 \mathrm{~N}$ sodium methoxide solution at $0^{\circ} \mathrm{C}$ overnight. After neutralization with a slight excess of Amberlite IR-120(H+), the filtrate was concentrated and was taken up in water. Examination of paper chromatogram showed the presence of glucose $\left(R_{F} 0.30\right)$, rhamnose $\left(R_{F} 0.52\right)$, two orthoesters $\left(R_{F} 0.60,0.65\right)$ and rutinose $\left(R_{F} \quad 0.20\right)$.

ii) Synthesis of rutinose by the Zemplén's method. A mixture of $2.08 \mathrm{~g}$ of $\beta-1,2,3,4$-tetraacetyl D-glucose, $2.1 \mathrm{~g}$ of 2,3,4-triacetyl $\alpha$-L-rhamnosyl bromide and $0.9 \mathrm{~g}$ of mercuric acetate in $30 \mathrm{ml}$ of absolute benzene was kept for four days at room temperature.

After washing with water several times and dried over calcium chloride, the benzene phase was evaporated in vacuo to a sirup and was taken up in methanol. Chromatographic examination of the sirup after deacetylation with sodium methoxide showed the presence of glucose $\left(R_{F} 0.30\right)$, rhamnose $\left(R_{F} 0.52\right)$ and two lesser components, rutinose $\left(R_{F}, 0.20\right)$ and unknown sugar $\left(R_{F}\right.$ 0.15). No orthoester products were detected.

2. Synthesis of 6- $\alpha$-L-rhamnosyl-D-glucose (rutinose) by Helferich reaction

i) Condensation of 2,3,4-tri-0-acetyl- $\alpha$-L-rhamnosyl bromide ${ }^{12\}}$ with $\beta-1,2,3,4$-tetra-0-acetyl- $\beta-D$ glucose.11) To a solution of $3.59 \mathrm{~g}$ of mercuric cyanide and $5.08 \mathrm{~g}$ of mercuric bromide in $99 \mathrm{ml}$ of absolute acetonitrile were added $9.57 \mathrm{~g}$ of $\beta-1,2,3,4$ tetraacetyl D-glucose and $9.9 \mathrm{~g}$ of $2,3,4$-triacetyl- $\alpha$-Lrhamnosyl bromide with stirring until the solution was complete.

After being kept overnight at room temperature the solvent was removed in vacuum below $30^{\circ} \mathrm{C}$ and the residual sirup was extracted with absolute chloroform and filtered.

The filtrate was washed three times with $1 \mathrm{~N}$ potassium bromide solution and dried over anhydrous sodium sulphate.

After filtering, the filtrate was concentrated in vacuo to an amorphous powder, which presumably

11) B. Helferich and W. Klein, Ann., 455, 173 (1927).

12) E. Fischer, M. Bergmann and A. Rabe, Ber., 53, 2362 (1920). 
contained rutinose heptaacetate as a main product. As it was failed to crystallize it from any solvent, it was deacetylated by dissolving in $80 \mathrm{ml}$ of $0.05 \mathrm{~N}$ sodium methylate in methanol on cooling, and allowed to stand overnight in an ice box.

Then the sodium was removed by stirring with a slightly excess of Amberlite resin IR-120(H+) until the solution became neutral, and the resin was filtered off and the filtrate was evaporated in vacuo to a sirup.

The sirup (7.55 g) was dissolved in $63 \mathrm{ml}$ of water to make a $10 \%$ solution, and chromatographed on column of carbon-celtite $(1: 1)$. Fractionation of the materials adsorbed on the column by gradient elution with water and aqueous ethanol was carried out.

The fractions which contained only rutinose were collected and evaporated to dryness giving amorphous, hygroscopic rutinose $(2 \mathrm{~g}) . \quad[\alpha]_{\mathrm{D}}^{20}-10^{\circ}(c 1, \mathrm{EtOH})$. In order to determine the configuration of the disaccharide, rutinose $(60 \mathrm{mg})$ was dissolved in $2 \mathrm{ml}$ of water and the solution was mixed with $2 \mathrm{ml}$ of a solution containing $300 \mathrm{mg}$ of sodium periodate.

Within $24 \mathrm{hr}$, the rotational value was constant, giving the specific rotation of the oxidized product of $-107^{\circ}\left(c 0.4, \mathrm{H}_{2} \mathrm{O}\right)$. In order to make acetyl rutinose, $1.6 \mathrm{~g}$ of well dried rutinose was dissolved in a mixture of $10 \mathrm{ml}$ of acetic anhydride and $2.5 \mathrm{~g}$ of anhydrous sodium acetate, and heated for 2 hours at $100^{\circ} \mathrm{C}$.

After cooling the solution was poured into ice water with stirring and left overnight in the refrigerator.

The amorphous precipitates were collected and washed with water and dried. It was crystallized from absolute ethanol in prisms, and yielded $0.9 \mathrm{~g}$; m.p. $167 \sim 169^{\circ}$ (from EtOH).

Its m.p. showed no depression on admixture with authentic specimen. $[\alpha]_{\mathrm{D}}^{15}-31.2^{\circ}$ Lit. $[\alpha]_{\mathrm{D}}^{15}-28.7^{\circ}$ Anal. Found: C, 50.31; H, 5.70. Calcd. for $\mathrm{C}_{26} \mathrm{H}_{36} \mathrm{O}_{17}$ : C, $50.32 ; \mathrm{H}, 5.80 \%$.

ii) Condensation of 2,3,4-tri-O-benzoyl- $\alpha$-Lrhamnosyl bromide ( $\alpha$-benzobromorhamnose) $)^{14}$ with $1,2: 3,5$-di-0-isopropylidene- $\alpha$-D-glucof uranose (isodiacetone glucose). ${ }^{13}$ ) To a solution of $0.356 \mathrm{~g}$ of mercuric cyanide and $0.504 \mathrm{~g}$ of mercuric bromide in $14 \mathrm{ml}$ of absolute acetonitrile were added $0.73 \mathrm{~g}$ of 1,2:3,5-diisopropylidene $\mathrm{D}$-glucose and $\alpha$-ben-

13) K. A. Petrov and E. E. Nifantiv, $Z h$. Obshch. Khim., 34(5), 1459 62 (1964).

14) R. K. Ness, H. G. Fletchner, Jr., and C.S. Hvdson, J. Am. Chem. Soc., 73, 296 (1952). zobromorhamnose with stirring and the mixture was allowed to stand for three hours. After the reaction was over, the solution was treated according to the procedure described above and $2.2 \mathrm{~g}$ of sirup was obtained.

As the sirup was failed to crystallize from any solvent, it was deacetylated and deacetonated as usual manner, and fractionated by carbon column as described above. Rutinose $(0.31 \mathrm{~g})$ was obtained as an amorphous hygroscopic powder, which was acetylated again as a usual manner to yield $\beta$-heptaacetate. It was recrystallized from ethanol. Its m.p. of $168^{\circ}$ showed no depression with authentic specimen.

\section{Synthesis of rutinose by Bredereck reaction ${ }^{10}$}

To the solution of $12.42 \mathrm{~g}$ of silver perchlorate10: in $108 \mathrm{ml}$ of anhydrous nitromethane was added $2 \mathrm{~g}$ of dried calcium sulphate. After while $35.4 \mathrm{~g}$ of 6 O-trityl- $\beta-1,2,3,4$-tetra-O-acetyl-D-glucose ${ }^{11}$ and $30 \mathrm{~g}$ of $\alpha$-acetobromorhamnose were dissolved in the solution with cooling and agitated vigorously for ten minutes at room temperature.

After the reaction was over, the mixture was filtrated in order to remove silver bromide and trityl perchlorate, and the filtrate was washed twice with an aqueous saturated sodium bicarbonate solution $\left(0^{\circ} \mathrm{C}\right)$ and several times with cold water and filtered. Chloroform was added to the filtrate and it was dried over anhydrous sodium sulphate. Then the filtrate was distilled off in vacuo, yielding $13.5 \mathrm{~g}$ of sirup which did not crystallized from any kind of solvent. On account of purification, it was chromatographed on carbon-celite column after deacetylation as usual manner.

Rutinose was obtained as an amorphous hygroscopic powder, yield $(2.6 \mathrm{~g})$. Upon acetylation it afforded a heptaacetate of m.p. $166 \sim 167^{\circ} \mathrm{C}$, which gave no depression on admixture with authentic specimen.

\section{Synthesis of 6-0- $\alpha$-L-rhamnosyl-D-galactose (robinobiose) by Helferich reaction.}

i) Condensation of $\alpha$-benzobromorhamnose with diacetonegalactose. ${ }^{15)}$ A solution containing $8.34 \mathrm{~g}$ of mercuric cyanide, $11.83 \mathrm{~g}$ of mercuric bromide, $17.1 \mathrm{~g}$ of diacetonegalactose and $35.48 \mathrm{~g}$ of $\alpha$-benzobromorhamnose was. allowed to stand three hours and was treated as described above. The residual sirup was crystallized easily from absolute ethanol in needles, yield $32.3 \mathrm{~g}(64.8 \%)$.

15) K. Freudenberg and R. M. Hixon, Ber., 56, 2119 (1923). 
The crystals were $6-\alpha-\left(2^{\prime}, 3^{\prime}, 4^{\prime}\right.$-tribenzoyl-Lrhamnosyl)-1,2:3,4-diisopropylidene-D-galactose (I): m.p. $162 \sim 164^{\circ} \mathrm{C},[\alpha]_{\mathrm{D}}^{15}+76^{\circ}$. Anal. Found: C, 65.05 ; $\mathrm{H}, 5.87$. Calcd. for $\mathrm{C}_{39} \mathrm{H}_{42} \mathrm{O}_{13}: \mathrm{C}, 65.18 ; \mathrm{H}, 5.85 \%$. In order to remove benzoyl groups of (I), $10 \mathrm{~g}$ of (I) was dissolved in $250 \mathrm{ml}$ of methanol and $25 \mathrm{ml}$ of $0.1 \mathrm{~N}$ sodium methylate solution was added to the solution, which was heated under reflux for five minutes and allowed to stand overnight at room temperature.

The solution was neutralized by the addition of the Amberite IR-120( $\left.\mathrm{H}^{+}\right)$to remove sodium ion and was extracted with chloroform in order to remove methylbenzoate.

The aqueous phase was made $0.1 \mathrm{~N}$ with sulphuric acid and was heated for hours at $70^{\circ} \mathrm{C}$ to release acetone group.

After cooling and adding barium carbonate in order to remove sulphate ion, the filtrate was concentrated in vacuo to a sirup which weighed $4.32 \mathrm{~g}$ $(90.18 \%) \cdot[\alpha]_{\mathrm{D}}^{15} 0^{\circ},[\alpha]_{\mathrm{D}}^{15}$ oxid $-113^{\circ}$.

Periodate oxidation of robinobiose should yield theoretically the same trialdehyde as in the case of rutinose oxidation.

From $[\alpha]_{D}^{15}$ oxid value of robinobiose it was thought to have $\alpha$-link. The well dried robinobiose $(0.63 \mathrm{~g})$ was acetylated as usual manner, giving an amorphous heptaacetate, $0.42 \mathrm{~g}: \mathrm{m} . \mathrm{p} .84 .5 \sim 85^{\circ} \mathrm{C}$. Lit. m.p. $83^{\circ} \mathrm{C}$. Anal. Found: C, 50.39: $\mathrm{H}, 5.78$. Calcd. for $\mathrm{C}_{26} \mathrm{H}_{36} \mathrm{O}_{17}$ : $\mathrm{C}, 50.32 ; \mathrm{H}, 5.80 \%$. To a solution of robinobiose heptaacetate $(500 \mathrm{mg}$ ) in $3.5 \mathrm{ml}$ of anhydrous chloroform $150 \mathrm{mg}$ of titanium tetra chloride was added.

A yellow precipitates were formed, which did not dissolve during the reaction. After being kept for three hours at room temperature the reaction mixture was poured into ice wate, whereupon the precipitates dissolved and the chloroform phase became almost colourless.

The latter was separated, washed with water, dried over calcium chloride and concentrated in vacuo.

The residual sirup was dissolved in small quantity of ether and kept at $0^{\circ} \mathrm{C}$ overnight. The colourless crystals of $\alpha$-acetochlororobinobiose were deposited, which were collected by filtration: yield, $200 \mathrm{mg}$; m.p. $\left.178 \sim 180^{\circ} \mathrm{C} ;[\alpha]_{D}^{15}-6.6^{\circ}(c) 3.02, \mathrm{HCl}_{3}\right)$. Lit. m.p. $178 \sim 180^{\circ} \mathrm{C}$. Anal. Found: C, 48.59; H, 5.65 . Calcd. for $\mathrm{C}_{24} \mathrm{H}_{32} \mathrm{O}_{15} \mathrm{Cl}: \mathrm{C}, 48.32 ; \mathrm{H}, 5.53 \%$.

ii) Condensation of $\boldsymbol{\alpha}$-acetobromorhamnose with diacetonegalactose. A mixture of $2.16 \mathrm{~g}$ of mercuric bromide, $1.52 \mathrm{~g}$ of mercuric cyanide, $2.8 \mathrm{~g}$ of di- acetonegalactose and $4.11 \mathrm{~g}$ of $\alpha$-acetobromorhamnose in $42 \mathrm{ml}$ of absolute acetonitrile was treated similarly as in the case of rutinose synthesis. The robinobiose fractions collected by carbon-column chromatography were evaporated to a sirup, yield $0.756 \mathrm{~g}(37.8 \%)$.

Acetylation and chlorination of $0.63 \mathrm{~g}$ of robinobiose gave $\alpha$-acetochloroderivative, m.p. $178 \sim 180^{\circ} \mathrm{C}$.

\section{Synthesis of 1-O- $\alpha$-L-rhamnosyl-D-fructose by Helferich reaction}

i) Condensation of 2,3,4-tri-0-benzoyl- $\alpha-L$ rhamnosyl bromide with $2,3: 4,5$-di-O-isopropylidene-D-fructopyranose. ${ }^{16)}$ A mixture of $4.445 \mathrm{~g}$ mercuric cyanide, $6.3 \mathrm{~g}$ of mercuric bromide, $9.2 \mathrm{~g}$ of $\beta$-diacetonefructose and $18.865 \mathrm{~g}$ of $\alpha$-benzobromorhamnose in $98 \mathrm{ml}$ of acetonitrile was allowed to stand overnight at room temperature. A part of needle crystals were deposited during the reaction. The reaction mixture was treated similarly as described in the case of robinobiose synthesis.

The sirup obtained was crystallized from absolute alcohol in needles, which were $1-\alpha$ - $(2,3,4$-tribenzoylL-rhamnosyl)-2, $3: 4,5$-diisopropylidene $\mathrm{D}$-fructopyranose (II) and yielded $15 \mathrm{~g}(69 \%):[\alpha]_{\mathrm{D}}+100^{\circ}$ (c 5, $\mathrm{CHCl}_{3}$ ); m.p. $190 \sim 191.5^{\circ} \mathrm{C}$ (from EtOH). Anal. Found: $\mathrm{C}, 65.31 ; \mathrm{H}, 5.80$. Calcd. for $\mathrm{C}_{39} \mathrm{H}_{43} \mathrm{O}_{13}$ : C, $65.09 ; \mathrm{H}, 5.847 \%$. The protecting groups of (II) were lost by the similar manner as described in the case of (I), and was obtained 1-O- $\alpha$-L-rhamnosyl-D-fructose as a sirup which was contaminated with a small amount of rhamnose and fructose. It was transferred to a mixture of carbon and celite $(1: 1)$, which was eluted with water and $2 \sim 5, \%$ ethanol.

The eluate containing only the disaccharide fraction was recovered as an amorphous solid: yield, $4.67 \mathrm{~g}$ $(61.3 \%) ;[\alpha]_{\mathrm{D}}-4.85^{\circ}\left(c 0.58, \mathrm{CHCl}_{3}\right),[\alpha]_{\mathrm{D}}^{15}$ oxid $-107^{\circ}$. The configuration of the dissccharide was assigned as $\alpha$-type. Upon acetylation as usual manner it gave only a sirup acetate. In order to characterize the disaccharide, phenylhydrazone of it was prepared. To $100 \mathrm{mg}$ of sample in $10 \mathrm{ml}$ of water were added $250 \mathrm{mg}$ of phenylhydrazine hydrochloride and $350 \mathrm{mg}$ of crystalline sodium acetate, and the mixture was heated at $100^{\circ} \mathrm{C}$ for 30 minutes. After cooling, needle crystals of slightly yellow colouration were separated, which were collected and dried to yield $50 \mathrm{mg}$ of the product, $193^{\circ} \mathrm{C}$ (decomp.) $(\mathrm{EtOH}) .[\alpha]_{15}^{\mathrm{D}} 20.4^{\circ} \quad(c$ 1, EtOH). Anal. Found: C, 57.20; H, 6.18; N, 11.21.

16) E. Pacsu, E. J. Wilson, Jr., and L. Graf, $J$. Am. Chem. Soc., 61, 2675 (1939). 
Calcd. for $\mathrm{C}_{24} \mathrm{H}_{31} \mathrm{O}_{8} \mathrm{~N}: \mathrm{C}, 57.25 ; \mathrm{H}, 6.16 ; \mathrm{N}, 11.13 \%$.

6. Synthesis of 6-0- $\alpha$-L-rhamnosyl-D-mannose by the Bredereck reaction

The disaccharide was synthesized similarly as in the case of rutinose synthesis by the Bredereck reaction. $8.5 \mathrm{~g}$ of silver perchlorate $73.6 \mathrm{ml}$ of nitromethane, $4.1 \mathrm{~g}$ of calcium sulphate, $13.5 \mathrm{~g}$ of $\alpha$ benzobromorhamnose and $24 \mathrm{~g}$ of 6 -O-trityl- $\beta-1,2,3,4-$ tetra-O-acetyl-D-mannose were used to obtain $26.6 \mathrm{~g}$ of the sirup which could not be crystallized from any kind of solvent. It was deacetylated as usual manner and $8.5 \mathrm{~g}$ of free sugar was obtaind. The sirup was found chromatographically to contain four compounds. The main component had $R_{F} 0.25$, and the minors were $R_{F} 0.31$ (glucose), $R_{F} 0.51$ (rhamnose) and $R_{F} 0.12$ (unknown), respectively. The sirup was dissolved in water to make $10 \%$ solution and fractionated on carbon-celite $(1: 1)$ column as usual manner.

The disaccharide fractions were collected and evaporated to an amorphous powder: yield, $1.73 \mathrm{~g}$; $[\alpha]_{\mathrm{D}}^{15}-8.2^{\circ}\left(c 1, \mathrm{H}_{2} \mathrm{O}\right)$. Sodium metaperiodate oxidation of sample should give the same trialdehyde as was obtained in the case of rutinose oxidation. $[\alpha]_{D}^{15}$ oxid $-110.3^{\circ}$. Thus the configuration of the disaccharide was assigned as $\alpha$-type. In order to characterize the disaccharide, 6-O- $\alpha$-L-rhamnosyl-Dmannose heptaacetate was prepared.

A mixture of $500 \mathrm{mg}$ of sugar, $14 \mathrm{ml}$ of acetic

17) D. D. Reynolds and W. L. Evans, J. Am. Chem. Soc., 62, 66 (1940). anhydride and $12 \mathrm{ml}$ of pyridine was allowed to stand for three days in the refrigerator.

Then the solution was poured into ice water and the amorphous precipitates was collected and crystallized from ethanol in needles: yield, $240 \mathrm{mg}$; m.p. $160^{\circ} \mathrm{C}$ (from ethanol); $[\alpha]_{\mathrm{D}}^{15}-5.2^{\circ}$ (c 3.8, $\mathrm{CHCl}_{\mathrm{g}}$ ). Anal. Found: C, 50.34; H, 5.80. Calcd. for $\mathrm{C}_{26} \mathrm{H}_{36} \mathrm{O}_{17}$ : C, $50.32 ; \mathrm{H}, 5.80 \%$.

7. Synthesis of 2-0- $\alpha$-L-rhamnosyl D-glucose (neohesperidose) by the Helferich reaction

A mixture of $3.59 \mathrm{~g}$ of mercuric cyanide, $5.08 \mathrm{~g}$ of

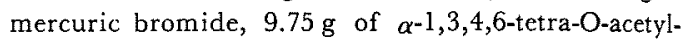
D-glucose and $9.89 \mathrm{~g}$ of $\alpha$-acetobromorhamnose in $100 \mathrm{ml}$ of acetonitrile was allowed to stand overnight at room temperature and was treated as usual manner.

As the sirup obtained could not be crystallized, it was deacetylated as usual manner and chromatographed on the carbon-celite column. The disaccharide fractions were collected and, on removal of the solvent, amorphous power was obtained: yield, $7 \mathrm{~g} ;[\alpha]_{\mathrm{b}}^{16}-5.4^{\circ}$ $\left(c 1, \mathrm{H}_{2} \mathrm{O}\right.$ ). In order to prepare acetyl derivative of the sugar, $1 \mathrm{~g}$ of the sample was acetylated as usual manner affording neohesperidose heptaacetate in needles: yield, $0.4 \mathrm{~g}$; m.p. $148 \sim 148^{\circ} \mathrm{C}(\mathrm{EtOH})$, lit. $151^{\circ} \mathrm{C} ;[\alpha]_{\mathrm{D}}^{15} 0^{\circ}$. Anal. Found: $\mathrm{C}, 50.07 ; \mathrm{H}, 5.71$. Calcd. for $\mathrm{C}_{26} \mathrm{H}_{32} \mathrm{O}_{17}: \mathrm{C}, 50.32 ; \mathrm{H}, 5.80 \%$.

Acknowledgement. The authors wish to express their thanks to Mr. Kusuo Narita of Shizuoka Pharmaceutical College for elemental analyses. 